\title{
INFLUÊNCIA DA COMPACTAÇÃO DO SOLO EM SUBSUPERFÍCIE SOBRE O CRESCIMENTO AÉREO E RADICULAR DE PLANTAS DE ADUBAÇÃO VERDE DE INVERNO(1)
}

\author{
M. M. L. MÜLLER ${ }^{(2)}$, G. CECCON ${ }^{(3)} \&$ C. A. ROSOLEM ${ }^{(4)}$
}

\begin{abstract}
RESUMO
A compactação do solo é um problema comum nas lavouras e que influi tanto no crescimento e na produtividade das culturas, como na conservação do solo e da água. A fim de estudar esse problema, cinco espécies de plantas de adubação verde de inverno (ervilhaca, nabo forrageiro, tremoço branco, aveia preta e aveia branca) foram cultivadas em quatro perfis de solo com crescentes níveis de compactação em subsuperfície (Ds: 1,31, 1,43, 1,58 e 1,70 $\mathrm{Mg} \mathrm{m}^{-3}$ ). 0 experimento foi realizado em vaso e sob condição de casa de vegetação na FCA/ UNE SP, em Botucatu (SP), em 1998, utilizando um LE de textura média. Com o aumento da compactação do solo, o comprimento e a matéria seca das raízes aumentaram acima da camada compactada e diminuíram abaixo dela, concentrando o sistema radicular das plantas próximo à superfície. 0 diâmetro radicular médio do tremoço e das duas avei as aumentou na camada compactada com o aumento da densi dade do solo, diminuiu para o caso da ervilhaca e não se alterou para o caso do nabo. 0 nabo forrageiro e a aveia preta sobressaíram-se com maiores valores de densidade de comprimento radicular na camada compactada e inferior e no vaso como um todo, mesmo com o aumento da compactação. Concluiu-se, neste estudo, que o nabo forrageiro e a aveia preta apresentaram-se como bons materiais, para melhorar as características de solos com compactação subsuperficial, mostrando vigor no crescimento de raízes dentro e abaixo da camada compactada do solo, devendo-se, entretanto, validar estes resultados no campo, em condições diferentes de clima e solo.
\end{abstract}

Termos de indexação: camada compactada, plantas de cobertura, raiz.

(1) Trabalho apresentado no XXVII Congresso Brasileiro de Ciência do Solo, realizado em Brasília (DF) de 12 a 16 de julho de 1999. Recebido para publicação em outubro de 1999 e aprovado em fevereiro de 2001.

(2) Engenheiro-Agrônomo, Doutorando na Faculdade de Ciências Agroveterinárias - FCA, Universidade Estadual Paulista - UNESP. Caixa Postal 237, CEP 18603-970 Botucatu (SP). E-mail: mmuller @fca.unesp.br

(3) Engenheiro-Agrônomo, Mestrando na FCA-UNESP.

(4) Professor do Departamento de Agricultura e Melhoramento Vegetal da FCA, UNESP. 


\title{
SUMMARY: INFLUENCE OF SUBSURFACE SOIL COMPACTION ON THE GROWTH OF THE AERIAL PARTS AND ROOTS OF WINTER GREEN MANURE SPECIES
}

\begin{abstract}
Soil compaction has been a very common problem on the fiedds, affecting growth and yiel d of the crops as well as soil and water conservation. In order to study this problem, five winter green manurespecies (Vicia sativa; Raphanus sativus; Lupinus al bus; Avena strigosa and Avena sativa) were cultivated in four soil profiles with increasing levels of subsurface compaction (soil bulk densities: 1.31, 1.43, 1.58 and $1.70 \mathrm{Mg} \mathrm{m}^{-3}$ ). Theexperiment was carried out in pots under greenhouse conditions at FCA/ UNESP in Botucatu, São Paul o in 1998, using a sandy loam Dark Red Latosol (Acrudox). As soil compaction increased, root length and dry matter increased above the compacted layer decreasing bel ow it, concentrating the root system of the plants cl ose to the surface Root mean diameter of L. albus, A. strigosa and A. sativa increased in the compacted layer with increasing soil density, decreased for V. sativa and was not altered for R. sativus. Raphanus sativus and A. strigosa showed the best performances on root growth, with higher values of root length density in both compacted and inferior soil layers, and in the pot as a whole, even with increasing soil compaction. This study shows that R. sativus and A. strigosa came out as good materials for ameliorating thecharacteristics of soils with subsurface compaction, showing vigor ous root growth inside and below the compacted laye These results, however, should be validated in the field, under different soil and climate conditions.
\end{abstract}

Index terms: compacted layer, cover crops, root.

\section{NTRODUÇÃO}

A estrutura do sol o influencia o crescimento das plantas de várias formas, sendo os efeitos sobre o alongamento radicular os mais claros e determinantes sobre a habilidade das raízes em extrair água e nutrientes do solo em quantidades adequadas. Excluindo as fissuras, os macroporos que são poros grandes, preferencial mente ocupados pelas raízes - e os poros biológicos (canais), os quais formam nichos para o crescimento das raízes, o al ongamento radicular no sol o só é possível quando a pressão radicular é maior que a impedância mecânica. Existem, ainda, outros fatores interrelacionados que influem no crescimento radicular, como a continuidade dos macroporos, a fertilidade química, a presença de microorganismos patogênicos ou simbióticos nos macroporos, a oxigenação do solo ea quantidade deágua disponível (Passioura, 1991).

Em sol o compactado, o número de macroporos é reduzido e a densidade é maior, o que, em solo seco, resulta em maior resistência física ao crescimento das raízes e decréscimo no potencial de água, e, em sol oúmi do, gera fal ta de oxigênio e, principalmente, el evadas concentrações de etileno na zona radicular, devidas à menor aeração (Marschner, 1995). O resultado de todas essas alterações no solo compactado é que as raízes sofrem modificações morfológicas e fisiológicas, por vezes específicas a cada espécie ou cultivar, a fim de se adaptarem.
Normalmente, a resistência mecânica do solo causa aumento de diâmetro das raízes na camada adensada (Mater echera et al ., 1992), e indicações de que as raízes diminuem de diâmetro para penetrar pequenos poros devem-se, provavel mente, ao fato de que a resistência mecânica do sol o também provoca proliferação de raízes laterais, as quais são mais finas (Russel \& Goss, 1974). Segundo Merotto J r. \& Mundstock (1999), as raízes podem crescer através dos poros e pontos de menor resistência, mas são incapazes de reduzir seu diâmetro para penetrar em poros menores.

A compactação do sol o reduz a infiltração de água no solo e aumenta o risco de erosãoe de déficit hídrico enutricional nas plantas, fazendo com que as raízes desenvolvam-se superficialmente (Rosolem et al., 1994; Moraes et al., 1995). Em solos onde as raízes finas podem explorar canais radiculares e fissuras existentes, culturas com raízes pivotantes são mais afetadas pela compactação que aquelas com raízes fasciculadas mais finas (Whiteley \& Dexter, 1982). Entretanto, raízes de maior diâmetro apresentam maior resistência ao encurvamento quando entram em sol o compactado (Whitel ey \& Dexter, 1984), o que, segundo Henderson (1989), é importante em solos deficientes em macroporos, onde as raízes necessitam mais deformar o solo do que explorar fissuras.

Quando as raízes que penetraram em camadas compactadas se decompõem, el as deixam canais que 
podem melhorar o movimento da água e a difusão dos gases no perfil do solo (Barley, 1954), além de servirem de caminhos para a penetração radicular das culturas. Segundo Dexter (1991), os "bioporos", derivados de raízes e de minhocas, fazem parte de processos naturais de melhoria das características do solo, devendo ser desenvol vidos e explorados, pois têm ótimo potencial para melhorar as características do sol o a custos moderados.

Os objetivos deste estudo foram: avaliar o crescimento radicular e aéreo dos adubos verdes de inverno, aveia branca, aveia preta, ervilhaca, nabo forrageiro e tremoço branco, quando submetidos a uma camada de solo compactado em subsuperfície, e identificar quais dessas espécies seriam mais indicadas para romper camadas de sol o compactado em subsuperfície.

\section{MATERIAL E MÉTODOS}

O experimento foi realizado em casa de vegetação no Departamento de Agricultura e Melhoramento Vegetal da FCA - UNESP/Botucatu em 1998. Durante 30 dias, foram cultivadas, em colunas de solo, duas plantas de cada um dos seguintes adubos verdes de inverno: ervilhaca (Vicia sativa L.); nabo forrageiro (Raphanus sativus L. var. ol. Metzg.); tremoço branco (Lupinus albus L.); aveia preta (Avena strigosa Schieb.), e aveia branca (Avena sativa L.). As col unas de solo, com $335 \mathrm{~mm}$ de altura, foram montadas com tubos de PVC de $100 \mathrm{~mm}$ de diâmetro

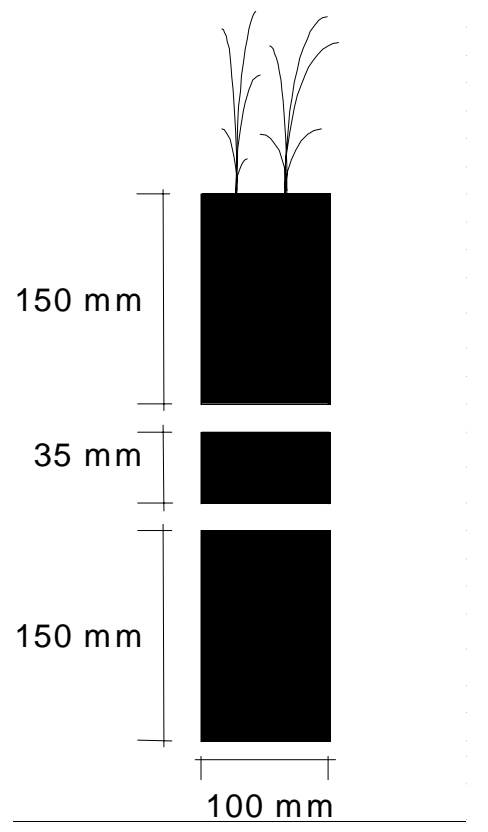

Figura 1. Ilustração esquemática dos vasos utilizados no experimento. interno, e constituídas detrês partes (Figura 1): uma superior e uma inferior, com $150 \mathrm{~mm}$ de altura, preenchidas com solo numa densidade próxima à encontrada no campo $\left(1,30 \mathrm{Mg} \mathrm{m}^{-3}\right)$, e uma intermediária, com 35 mm de altura, na qual o solo foi compactado.

A terra foi coletada na camada superficial (0$20 \mathrm{~cm}$ ) de um Latossolo Vermel ho-E scuro álico textura média (Carvalho et al., 1983) e, após secagem ao ar, foi passada em peneira com malha de $4 \mathrm{~mm}$. Foram então separadas amostras para determinação das características químicas (Raij \& Quaggio, 1983), da granulometria (EMBRAPA, 1997) e dos teores de água na capacidade de campo e no ponto de murcha permanente (EMBRAPA, 1997), obtidos noA parel ho Extrator de Richards (Quadro 1).

Em seguida, foi feita calagem, calculada para atingir $70 \%$ de saturação por bases do solo. A terra, então, foi umedecida a $80 \%$ da capaci dade de campo e armazenada em sacos plásticos para incubação úmida por 30 dias. Passado esse período, foram adicionados $50 \mathrm{mg} \mathrm{dm}^{-3}$ de N (uréia), $200 \mathrm{mg} \mathrm{dm}^{-3}$ de $P$ (superfosfato simples) e $150 \mathrm{mg} \mathrm{dm}^{-3}$ de $\mathrm{K}$ (cloreto de potássio), ea água foi corrigida para $75 \%$ da capacidade de campo (85 $\left.\mathrm{g} \mathrm{kg}^{-1}\right)$, iniciando-se a compactação do solo nos anéis intermediários, o preenchimento e a montagem das colunas, unindo as partes com fita adesiva.

A compactação no anel inter mediário deu-se com o uso de um equipamento compactador, conforme descrito por Moraes (1988). Variando o número de gol pes com o equipamento, as amostras de sol o foram

\section{Quadro 1. Principais características do solo} utilizado no experimento

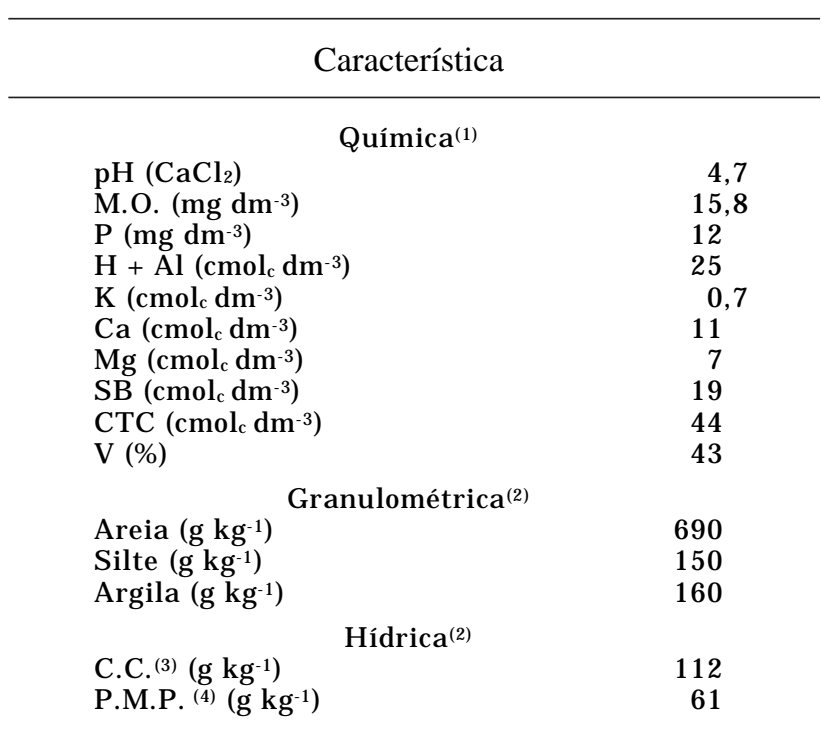

(1) Raij \& Quaggio (1983). (2) EMBRAPA (1997). ${ }^{(3)}$ Água retida a $-0,06 \mathrm{MPa}$. ${ }^{(4)}$ Água retida a $-1,50 \mathrm{MPa}$. 
compactadas com diferentes intensidades, obtendose, ao final, as seguintes densidades de solo: 1,43; 1,58; $1,70 \mathrm{Mg} \mathrm{m}^{-3}$. O quarto nível de compactação nível zero - foi obtido por meio do preenchimento com solo da coluna de PVC, o que, resultou em densidade de 1,31 $\mathrm{Mg} \mathrm{m}^{-3}$.

Antes da montagem das colunas, foi colada uma borda periférica de fita adesiva de cerca de $2,5 \mathrm{~cm}$ na superfície do anel compactado, a fim de evitar o crescimento de raízes na interface da camada compactada com a parede do recipiente. Mesmo assim, observou-se o crescimento de al gumas raízes nesta região, as quais foram consideradas pertencentes às camadas superiores das colunas.

Para caracterizar os diferentes níveis de compactação, fez-se um ensai o com quatro repetições, tendo sido utilizados anéis de aço dentro da massa de solo a ser compactado para, então, determinar a densidade do solo, pelo método do anel volumétrico (EMBRAPA, 1997), e a resistência mecânica do solo à penetração, aferida por um penetrômetro de bolso com ponteira cônica (base do cone de $18 \mathrm{~mm}$, altura de $40 \mathrm{~mm}$ e ângulo do vértice de $23^{\circ}$ ) (Quadro 2).

Após o período de 30 dias de cultivo, fez-se a coleta da parte aér ea das plantas, que, depois de secas em estufa $\left(70^{\circ} \mathrm{C}\right.$ por $\left.48 \mathrm{~h}\right)$, foram pesadas, a fim de quantificar o acúmulo de matéria seca da parte aérea. O sistema radicular foi dividido em três porções, correspondentes às camadas: superior, intermediária e inferior dos vasos, sendo estas separadas do solo por lavagem, utilizando-se um aparel ho lavador de raízes semel hante ao descrito por Smucker et al. (1982).

Cada porção foi limpa em água corrente sob peneira e armazenada sob refrigeração $\left( \pm 5^{\circ} \mathrm{C}\right)$ em solução com $0,30 \mathrm{~m}^{3}$ de etanol por $\mathrm{m}^{3}$ de água. As porções de raízes das camadas superiores dos vasos, por apresentarem um volume grande, foram

\section{Quadro 2. Resistência mecânica do solo à penetração, considerando sua densidade a $85 \mathrm{~g} \mathrm{~kg}^{-1}$ de umidade}

\begin{tabular}{cc}
\hline Densidade & Resistência \\
\hline $\mathrm{Mg} \mathrm{m}^{-3}$ & $\mathrm{MPa}$ \\
1,31 & 0,10 \\
1,41 & 0,34 \\
1,58 & 0,79 \\
1,70 & 1,34 \\
\hline
\end{tabular}

subdivididas, sendo retiradas alíquotas representativas. As raízes da camada compactada e da inferior, bem como as alíquotas da camada superior, tiveram o comprimento e o diâmetro radicular médio estimados por meio de leitura ótica com scanner e uso do programa "Win Mac Rhyzo" v.3.8(5).

Por fim, determinou-sea massa total da matéria seca de raízes após secagem em estufa $\left(70^{\circ} \mathrm{C}\right.$ por $48 \mathrm{~h}$ ) e, por meio da relação entrea massa da matéria seca das alíquotas e a massa total da matéria seca de raízes, determinou-se o comprimento radicular da porção de raízes da camada superior. De posse dos resultados de comprimento, fez-se o cálculo de densidade de comprimento radicular por meio da divisão do comprimento encontrado em cada porção pelo volume do respectivo anel de PVC, ou seja, $1.178 \mathrm{~cm}^{3}$, para a camada superior e inferior, e $275 \mathrm{~cm}^{3}$, para a camada compactada.

Os resultados foram submetidos à análise de variância, considerando-se um delineamento experimental em bl ocos completos casualizados, num esquema fatorial $5 \times 4$ (cinco espécies vegetais e quatro níveis de compactação do solo) com quatro repetições. As médias obti das foram comparadas pelo teste t de Student, a 5\%.

\section{RESULTADOS E DISCUSSÃO}

Foram observadas interações significativas entre os fatores espécie e densidade do solo para as variáveis estudadas, com exceção do diâmetro radicular médio na camada superior dos vasos. Os dados de massa de matéria seca de raízes das plantas (MSR), considerando as densidades de solo na camada compactada, são mostrados no quadro 3. Nota-se que, para todas as espécies, o aumento da densidade na camada compactada provocou aumento da MSR na camada superior e diminuição na camada inferior dos vasos, ou seja, houve concentração das raízes próximo à superfície, o que está de acordo com observações de Moraes et al. (1995).

É possível notar que as espécies nabo forrageiro, aveia preta e aveia branca, em ordem decrescente, apresentaram os maiores acúmulos de MSR na camada compactada e na inferior dos vasos, mostrando maior potencial para aumentar a aeração e diminuir a compactação do solo após seu cultivo. O nabo destacou-se das outras espécies quanto ao acúmulo de MSR tanto na camada compactada como na inferior no maior nível de compactação, além de mostrar bom acúmulo na camada superior. A aveia preta foi levemente superior à aveia branca, mostrando-se também menos sensível ao aumento da compactação.

(5) REGENTE INSTRuMENT INC. 165, Fatima Ave., Quebec, Qc. G1P 2C7, Canadá. 
Quadro 3. Matéria seca de raízes das plantas de adubo-verde de inverno, considerando as densidades de solo na camada compactada

\begin{tabular}{|c|c|c|c|c|c|}
\hline $\begin{array}{l}\text { Densidade na camada } \\
\text { compactada }\end{array}$ & Ervilhaca & $\begin{array}{l}\text { Nabo } \\
\text { forrageiro }\end{array}$ & $\begin{array}{c}\text { Tremoço } \\
\text { branco }\end{array}$ & $\begin{array}{l}\text { Aveia } \\
\text { preta }\end{array}$ & $\begin{array}{c}\text { Aveia } \\
\text { branca }\end{array}$ \\
\hline \multirow[t]{2}{*}{$\mathrm{Mg} \mathrm{m}^{-3}$} & & 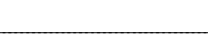 & $-g$ & 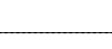 & - \\
\hline & \multicolumn{5}{|c|}{ Camada superior [D.M.S. $=0,13(5 \%) ;$ C.V. $=18 \%$ ] } \\
\hline $\begin{array}{l}1,31 \\
1,43 \\
1,58 \\
1,70\end{array}$ & $\begin{array}{l}0,56 \\
0,60 \\
0,62 \\
0,73\end{array}$ & $\begin{array}{l}0,36 \\
0,67 \\
0,51 \\
0,78\end{array}$ & $\begin{array}{l}0,25 \\
0,17 \\
0,40 \\
0,40\end{array}$ & $\begin{array}{l}0,39 \\
0,36 \\
0,57 \\
0,80\end{array}$ & $\begin{array}{l}0,16 \\
0,18 \\
0,32 \\
0,55\end{array}$ \\
\hline & \multicolumn{5}{|c|}{ Camada compactada [D.M.S. $=0,02(5 \%) ;$ C.V. $=41 \%]$} \\
\hline $\begin{array}{l}1,31 \\
1,43 \\
1,58 \\
1,70\end{array}$ & $\begin{array}{l}0,04 \\
0,02 \\
0,02 \\
0,01\end{array}$ & $\begin{array}{l}0,08 \\
0,03 \\
0,05 \\
0,07\end{array}$ & $\begin{array}{l}0,02 \\
0,02 \\
0,01 \\
0,02\end{array}$ & $\begin{array}{l}0,04 \\
0,04 \\
0,05 \\
0,04\end{array}$ & $\begin{array}{l}0,05 \\
0,03 \\
0,02 \\
0,04\end{array}$ \\
\hline & \multicolumn{5}{|c|}{ Camada inferior [D.M.S. $=0,06$ (5\%); C.V. $=33 \%$ ] } \\
\hline $\begin{array}{l}1,31 \\
1,43 \\
1,58 \\
1,70\end{array}$ & $\begin{array}{l}0,09 \\
0,06 \\
0,02 \\
0,00\end{array}$ & $\begin{array}{l}0,37 \\
0,28 \\
0,28 \\
0,08\end{array}$ & $\begin{array}{l}0,06 \\
0,02 \\
0,03 \\
0,02\end{array}$ & $\begin{array}{l}0,32 \\
0,16 \\
0,12 \\
0,07\end{array}$ & $\begin{array}{l}0,15 \\
0,11 \\
0,10 \\
0,02\end{array}$ \\
\hline
\end{tabular}

A despeito de mostrar bom acúmulo de MSR na camada superior, por vezes os maiores índices, a ervilhaca sofreu grande redução na MSR na camada compactada e na inferior com o aumento da densidade do solo, mostrando-se mais sensível à compactação. J á o tremoço branco foi menos afetado pelo aumento da densidade do solo, com menor variaçãono acúmulo de MSR, decorrente da variação da densidade do solo; entretanto, mostrou sempre baixo acúmulo deMSR, o que nãoéinteressantepara a rotação de culturas em áreas com compactação subsuperficial, uma vez que irá deixar menor número de poros biológicos para as culturas posteriores.

Os resultados de densidade de comprimento radicular (DCR) foram compatíveis com os de acúmulo de matéria seca de raízes (Figura 2). 0 tremoço branco apresentou um sistema radicular pouco desenvolvido, com valores de DCR significativamente menores que os das demais espécies. A ervilhaca apresentou, natural mente, um sistema radicular mais raso que o das outras espécies, revelando maiores valores de DCR na camada superior e percentuais reduzi dos na camada compactada e na inferior, em relação aos de outras espécies, mesmo no menor nível de densidadedosolo. O nabo forrageiro e a aveia preta foram as espécies que se sobressaíram, associando maiores valores de DCR tanto na camada inferior como na compactada, bem como valores elevados de DCR no vaso como um todo. Numa posição intermediária, a aveia branca mostrou valores elevados de DCR na camada compactada.

Considerando os dados de DCR, o nabo forragei ro e a aveia preta deixaram no sol o maior extensão de bioporos após a decomposição das raízes, principalmentena camada compactada ena inferior. Segundo Barley (1954), esses bioporos são importantes para mel horar o movimento da água e à difusão dos gases no perfil do solo, o que resulta em melhores condições de crescimento radicular para as culturas cultivadas na seqüência.

O aumento da densidade do solo provocou aumento do diâmetro radicular médio na camada compactada para o tremoço branco, aveia preta e aveia branca (Quadro 4), o que vai ao encontro dos resultados de Merotto J r. \& Mundstock (1999) e da hipótese de Russel \& Goss (1974) dequea resistência mecânica do solo normalmente causa aumento do diâmetro radicular dentro da camada adensada. Para o nabo, não se notou o mesmo efeito, e, para a ervilhaca, notou-se, na verdade, uma tendência de efeito contrário, o que, segundo Materechera et al. (1992), pode ser resultado da proliferação de raízes laterais finas, causada pela inibição do al ongamento na região apical das raízes, e não da diminuição propriamente dita do diâmetro das raízes. 


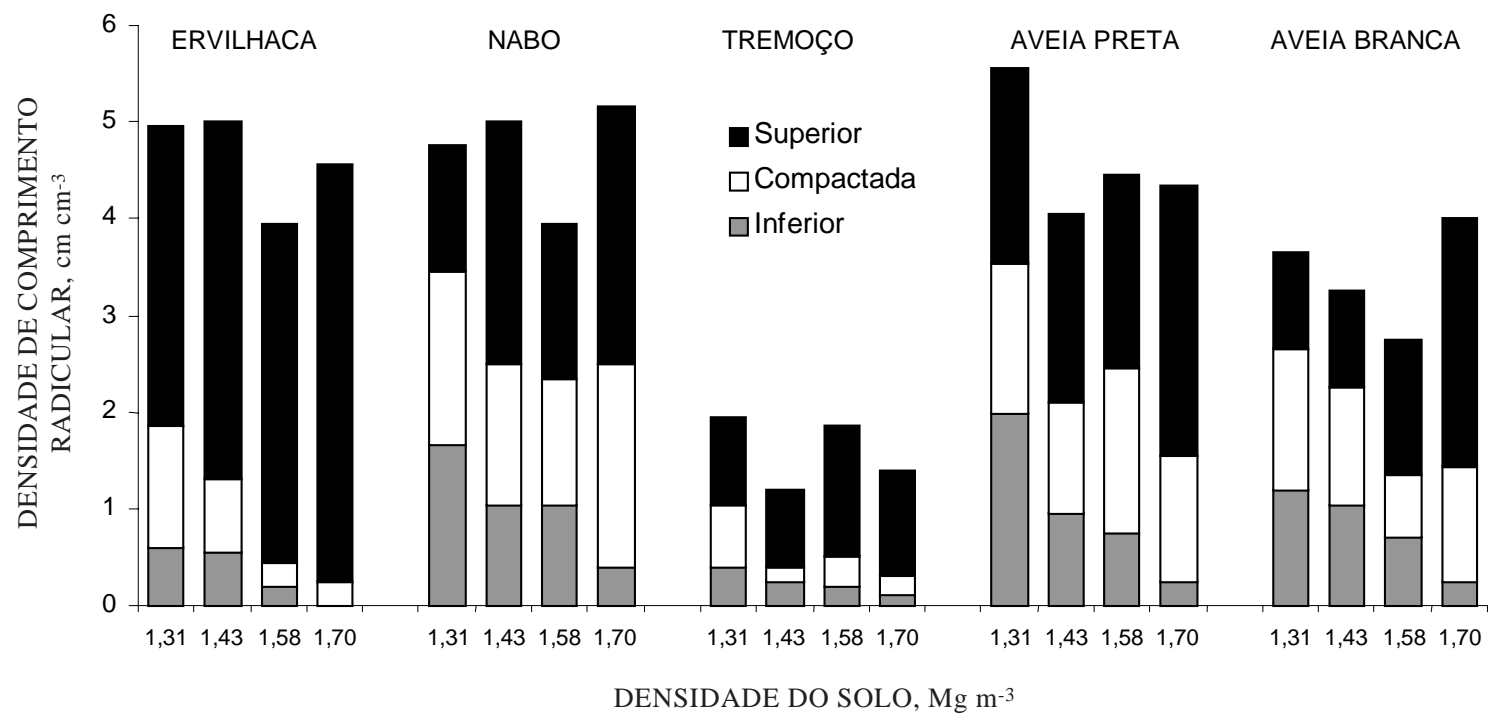

Figura 2. Distribuição da densidade de comprimento radicular das plantas de adubo-verde de inverno nas camadas dos vasos, considerando as densidades do solo na camada compactada.

Quadro 4. Diâmetro médio radicular das plantas de adubo-ver de de inverno na camada compactada do solo, considerando a densidade do solo

\begin{tabular}{|c|c|c|c|c|c|}
\hline Densidade & Ervilhaca & Nabo forrageiro & Tremoço branco & Aveia preta & Aveia branca \\
\hline $\mathrm{Mg} \mathrm{m}^{-3}$ & & & $\mu m^{(1)}$ & & - \\
\hline 1,31 & 51 & 33 & 52 & 35 & 33 \\
\hline 1,43 & 66 & 34 & 62 & 35 & 35 \\
\hline 1,58 & 48 & 32 & 61 & 43 & 35 \\
\hline 1,70 & 48 & 32 & 60 & 45 & 44 \\
\hline
\end{tabular}

(1) D.M.S. =0,004 (5\%); C.V. (6,3\%).

A ervilhaca e otremoço branco, ajos desempenhos de crescimento radicular foram inferiores, mostraram diâmetros radiculares maiores queos das outras espécies. Estes dados sugerem prel iminarmente que, para o grupo de espécies testadas, as espécies com menor diâmetro médio de raízes foram mais eficientes na tarefa de crescer através da camada compactada, o que se evidencia pelos exemplos extremos do nabo forragei ro e do tremoço branco.

Quanto ao acúmulo de matéria seca da parte aérea (MSPA), houve resposta diferenciada das espécies, dependendo da densidade do solo na camada compactada (Quadro 5). Houve leve (nãosignificativo) aumento na MSPA da ervilhaca com o aumento da densidade, o inverso ocorrendo para a aveia branca, cuja MSPA diminuiu, sendo significativamente menor na densidade $1,70 \mathrm{Mg} \mathrm{m}^{-3}$ que nas demais. Para o nabo forrageiro, percebeu-se também uma tendência de diminuição no acúmulo de MSPA, o qual foi significativamente menor nos dois maiores níveis de densidade do solo.
Houve diminuiçãosignificativa da MSPA da aveia preta quando a densidade do sol o foi de $1,58 \mathrm{Mg} \mathrm{m}^{-3}$; contudo, a densidade de $1,70 \mathrm{Mg} \mathrm{m}^{-3}$ resultou num acúmulo de MSPA estatisticamente igual ao observado no menor nível de densidade. O tremoço branco apresentou tendência de diminuição de MSPA com aumento da compactação, sendo a MSPA significativamente menor em 1,58 que em $1,31 \mathrm{Mg} \mathrm{m}^{-3}$, mas, na densidade de $1,70 \mathrm{Mg} \mathrm{m}^{-3}$, a MSPA foi significativamente maior que nas menores densidades. Nestes dois casos, a evol ução do acúmulo de MSPA com o aumento da densidade do solo na camada compactada não permite concluir nem pela diminuição nem pelo aumento do acúmul o de MSPA, o que, de acordo com Eavis (1972), pode ter ocorrido pelo fato de serem complexas as interações das propriedades físicas do solo e o crescimento das plantas, podendo gerar respostas das plantas que não as esperadas.

Nada obstante, é possível notar que a densidade de $1,43 \mathrm{Mg} \mathrm{m}^{-3}$ resultou em maior acúmulo MSPA 


\section{Quadro 5. Massa de matéria seca da parte aérea das plantas de adubo-verde de inverno, consi derando as densidades de solo na camada compactada}

\begin{tabular}{cccccc}
\hline Densidade & Ervilhaca & Nabo forrageiro & Tremoço branco & Aveia preta & Aveia branca \\
\hline$M^{-3}$ m $^{-3}$ & 1,31 & 2,84 & $g^{(1)}$ & & \\
1,31 & 1,45 & 2,97 & 1,97 & 1,21 & 1,38 \\
1,43 & 1,47 & 2,39 & 1,82 & 1,40 & 1,42 \\
1,58 & 1,57 & 2,45 & 2,28 & 1,04 & 1,23 \\
1,70 & & & & 1,19 & 0,94 \\
\hline
\end{tabular}

(1) D.M.S. =0,29 (5\%); C.V. (11\%).

que a densidade de $1,31 \mathrm{Mg} \mathrm{m}^{-3}$ para todas as espécies, com exceção do tremoço branco, o que vai ao encontro de observações de Gediga (1991), que cita aumento de produção de biomassa aérea de milho quando houve aumento da compactação do subsolo até um nível intermediário. Uma possível explicação para este resultado seria o fato de que, para ambas as situações, as densidades intermediárias podem ter promovido melhor contato soloraiz, resultando em mel hores condições de absor ção de água e nutrientes sem prejudicar, de forma drástica, o crescimento das raízes, considerando que o fornecimento de água às plantas não foi limitante nos dois experimentos.

Verificou-se, ainda, que o nabo forrageiro foi a espécie com maior acúmulo de matéria seca da parte aérea em todas as densidades. Este resultado relaciona-se com o fato de ter esta espécie apresentado melhor distribuição radicular em profundidade no solo (comprimento radicular e matéria seca deraízes) em relaçãoàs outras espécies, conferindo-lhe melhores condições de crescimento, além de concordar com dados de experimentos, nos quais o nabo forrageiro produziu mais massa de matéria seca que o tremoço branco, que a ervilhaca e que a aveia preta (Derpsch et al., 1991).

Dentre as espécies estudadas e em condições de clima favoráveis ao seu desenvolvimento, o nabo forrageiro e a aveia preta surgiram como bons materiais para adubação verde de inverno em situações de compactação subsuperficial do solo. Essas plantas, com maior habilidade em penetrar suas raízes em camadas compactadas e sistemas radiculares mais desenvolvidos em profundidade, oferecem melhores condições de funcionarem como processos naturais de melhoria das características do solo, deixando no solo maior número de bioporos após seu cultivo, o que favorece o desenvolvimento das culturas em seqüência e proporciona a recuperação da estrutura do solo em subsuperfície. Esses dados devem, entretanto, ser validados no campo, em condições diferentes de di ma (temperatura e precipitação) e de solo para que, então, estas espécies possam ser recomendadas com maior segurança para rotação de culturas em áreas com compactação subsuperficial .

\section{CONCLUSÕES}

1. A compactação do solo em subsuperfície prejudicou o crescimento radicular das espécies estudadas, concentrando as raízes perto da superfície do solo.

2. O nabo forrageiro e a aveia preta foram as melhores, dentre as espécies estudadas, para atravessar a camada de sol o compactado e explorar o volume de sol o abaixo dela.

3. Os dois maiores níveis de compactação subsuperficial dosolo, para o caso do nabo forrageiro, e somente o mai or nível, para o caso da aveia branca, provocaram diminuição significativa da produção de matéria seca da parte aérea das plantas. No caso da ervilhaca, a compactação subsuperficial não influenciou significativamente a produção de parte aérea.

4. Para as espécies aveia preta etremoço branco, não se verificou influência da compactação subsuperficial do solo na produção de parte aérea das plantas.

\section{LITERATURA CITADA}

BARLEY, K.P. Effect of root growth and decay on the permeability of a synthetic sandy loam. Soil Sci., 78:205-210, 1954.

CARVALHO, W.A.; ESPINDOLA, C.R. \& PACCOLA, A.A. Levantamento de solos da Fazenda Lageado, Estação Experimental "Presidente Médici". Botucatu, Universidade Estadual de São Paulo, 1983. p.95. 
DERPSCH, R.; ROTH, C.H.; SIDIRAS, N. \& KÖPKE, U. Controle da erosão no Paraná, Brasil: Sistemas de cobertura do solo, plantio direto e preparo conservacionista do sol o. Eschborn, GTZ GmbH, 1991. 268p.

DEXTER, A.R. Amelioration of soil by natural processes. Soil \& Till. Res., 20:87-100, 1991.

EAVIS, B.W. Soil physical conditions affecting seedling root growth. I. Mechanical impedance, aeration and moisture availability as influenced by bulk density and moisture levels in a sandy loam soil. Plant Soil, 36:613-622, 1972.

EMPRESA BRASILEIRA DE PESQUISA AGROPECUÁRIA EMBRAPA. Centro Nacional de Pesquisa de Solos. Manual de métodos de análise de solo. 2.ed. Rio de J aneiro, 1997. 212p.

GEDIGA, K. Influence of subsoil compaction on the uptake of ${ }^{45} \mathrm{Ca}$ from the soil profile and on maize yield. Soil \& Till. Res., 19:351-355, 1991.

HENDERSON, C.W. Lupin as a biological plough: evidence for, and effects on wheat growth and yield. Aust. J . Exp. Agric., 29:99-102, 1989.

MARSCHNER, H. Mineral nutrition of higher plants. 2.ed. London, Academic Press, 1995. p.508-536.

MATERECHERA, S.A.;ALSTON,A.M.; KIRBY,J .M. \& DEXTER, A.R. Influence of root diameter on the penetration of seminal roots into a compacted subsoil. Plant Soil, 144:297303, 1992.

MEROTTO J r., A. \& MUNDSTOCK, C.M. Wheat root growth as affected by soil strength. R. Bras. Ci. Solo, 23:197-202, 1999.
MORAES, M.H. Efeitos da compactação em algumas propriedades físicas do solo e no desenvolvimento do sistema radicular de plantas de soja (Glycine max (L.) Merrill). Piracicaba, Escola Superior de Agricultura Luiz de Queiroz, 1988. 114p. (Tese de Mestrado)

MORAES, M.H.; BENEZ, S.H. \& LIBARDI, P.L. Efeitos da compactação em al gumas propriedades físicas do solo e seu reflexo no desenvolvimento das raízes de plantas de soja. Bragantia, 54:393-403, 1995.

PASSIOURA, J.B. Soil structure and plant growth. Aust. J . Soil Res., 29:717-728, 1991.

RAIJ , B. Van \& QUAGGIO, J .A. Métodos de análise de solo para fins de fertilidade. B. Tec. Inst. Agron., 81:1-31, 1983.

ROSOLEM, C.A.;VALE, L.S.R.; GRASSI FILHO, H.\& MORAES, M.H. Sistema radicular e nutrição do milho em função da calagem e da compactação do sol o. R. Bras. Ci. Sol o, 18:491497, 1994

RUSSELL, R.S. \& GOSS, M.J. Physical aspects of soil fertility The response of roots to mechanical impedance. Neth. J . Agric. Sci., 22:305-318, 1974.

SMUCKER, A.J.M.; MCBURNEY, S.L. \& SRIVASTAVA, A.K. Quantitative separation of roots from compacted soil profiles by the hidropneumatic elutriation system. Agron. J., 74:500-503, 1982.

WHITELEY, G.M. \& DEXTER, A.R. Root development and growth of oilseed, wheat and pea crops on tilled and nontilled soil. Soil \& Till. Res., 2:379-393, 1982

WHITELEY, G.M. \& DEXTER, A.R. The behaviour of roots encountering cracks in soil. I. Experimental methods and results. Plant Soil, 77:141-149, 1984. 